\title{
Xeroderma pigmentosum and band-shaped nodular corneal dystrophy
}

\author{
JEFFREY FREEDMAN \\ From the Department of Ophthalmology, University of Witwatersrand, South Africa
}

SUMMARY A case of xeroderma pigmentosum with associated band-shaped nodular dystrophy of the cornea is discussed. Band-shaped nodular dystrophy of the cornea usually occurs in elderly Bantu men. Band-shaped nodular dystrophy in a young Bantu man suffering from a genetically determined solar sensitive disease lends credence to the possibility that band-shaped nodular dystrophy is a solar sensitive disease, as has so often been postulated.

Xeroderma pigmentosum is an inherited progressive precancerous disorder of skin and mucous membranes. The disease was first described by Kaposi in 1874 and is said to be rare in Africans, in whom only 16 cases have been reported involving Bantus (Loewenthal and Trowell, 1938; Targousky and Loewenthal, 1956; Harris and Keet, 1960; Sevel, 1963). Band-shaped nodular dystrophy of the cornea was first described in the Bantu by Etzine and Kaufmann (1964) and further cases were subsequently reported by Freedman (1973).

This paper concerns the occurrence of both xeroderma pigmentosum and band-shaped nodular dystrophy in a 30-year-old Bantu.

\section{Case report}

A 30-year-old man (Fig. 1) presented to the St John Eye Hospital, Baragwanath, with the complaint of poor vision since birth (Case 1). On examination, his visual acuity was hand movements at half a metre in both eyes. Unlike other cases of xeroderma pigmentosum he was not markedly photophobic. Both corneas showed diffuse non-vascularised opacities, opacification extending from the epithelium through to superficial stroma. In addition both corneas showed the presence of stage 2 bandshaped nodular dystrophy (Fig. 2). The characteristic juxta-limbal pigmentation as seen in band-shaped nodular dystrophy was also present. No details of the anterior chamber could be seen, and no view of the lenses or fundi was obtainable.

The patient's 13-year-old brother had undergone

Address for reprints: J. Freedman, FRCS, Department of Ophthalmology, University of Witwatersrand Medical School. Hillbrow,
Johannesburg, South Africa

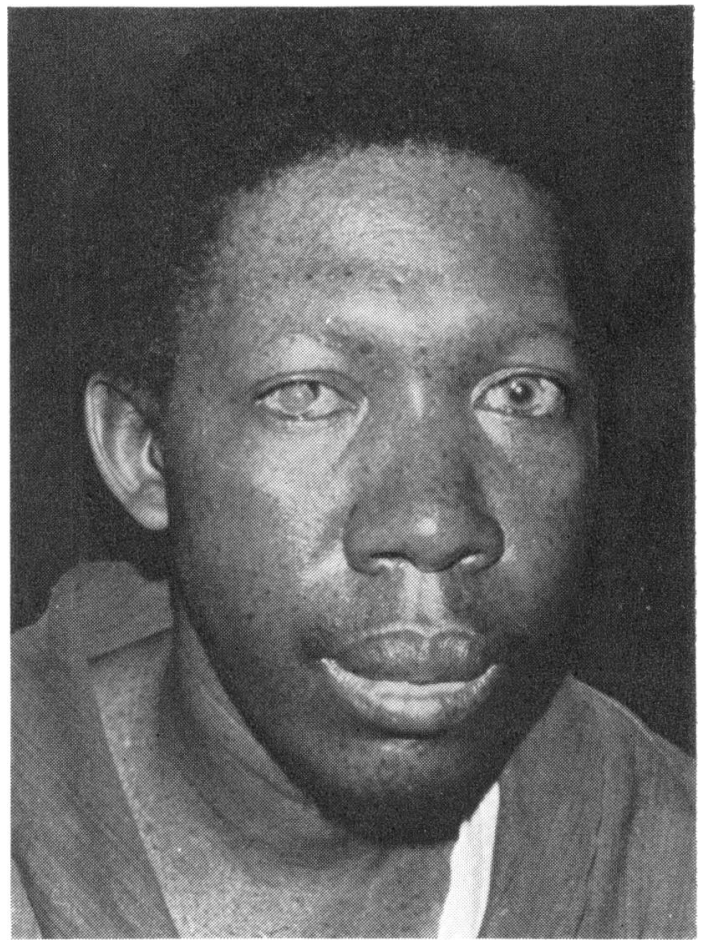

Fig. 1 Eldest brother with xeroderma pigmentosum

a corneal transplant for total corneal opacities 2 months earlier (Case 2). A third brother aged 8 years showed some interesting clinical features (Case 3). His left eye had an opaque cornea similar in appearance to the corneas of his 2 brothers (Fig. 3). His right cornea was completely clear, and on this side he had a ptotic lid. All 3 brothers were 


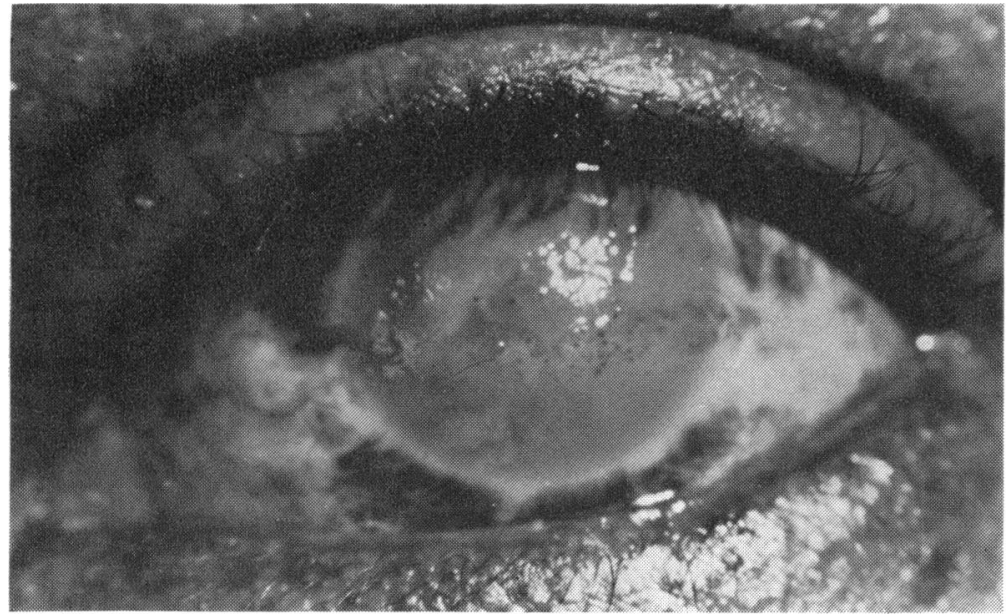

Fig. 2 Band-shaped nodular dystrophy combined with opacity of cornea due to xeroderma pigmentosum

found to have xeroderma pigmentosum with the typical skin lesions characterised by multiple, fine hyperpigmented macular lesions of the skin (Figs. $4,5)$.

The patient underwent a right-sided penetrating $8 \mathrm{~mm}$ keratoplasty. Histological examination of the corneal button showed the changes characteristic of band-shaped nodular dystrophy. Hyaline-like deposits were found to be present in the superficial stroma, with destruction of the basement membrane of the epithelium. Apart from some irregularity of the superficial stroma, the rest of the corneal stroma appeared to be normal. The typical histological changes of xeroderma pigmentosa as seen in other cases, and characterised by irregularity of the superficial corneal stroma, were chiefly masked by the presence of the hyaline deposits (Figs. 6, 7, 8).

\section{Discussion}

The case shows some unusual features related to both xeroderma pigmentosum and band-shaped nodular dystrophy. Xeroderma pigmentosum tends to cause ocular symptoms more commonly in Black than in Caucasoid patients, the incidence of ocular involvement being $80 \%$ in the former and $30 \%$ in the latter (Giller and Kaufmann, 1959), with possible greater susceptibility to ultraviolet rays of ocular and periocular tissues in the Black patients. Certainly the case reported in this study showed relatively

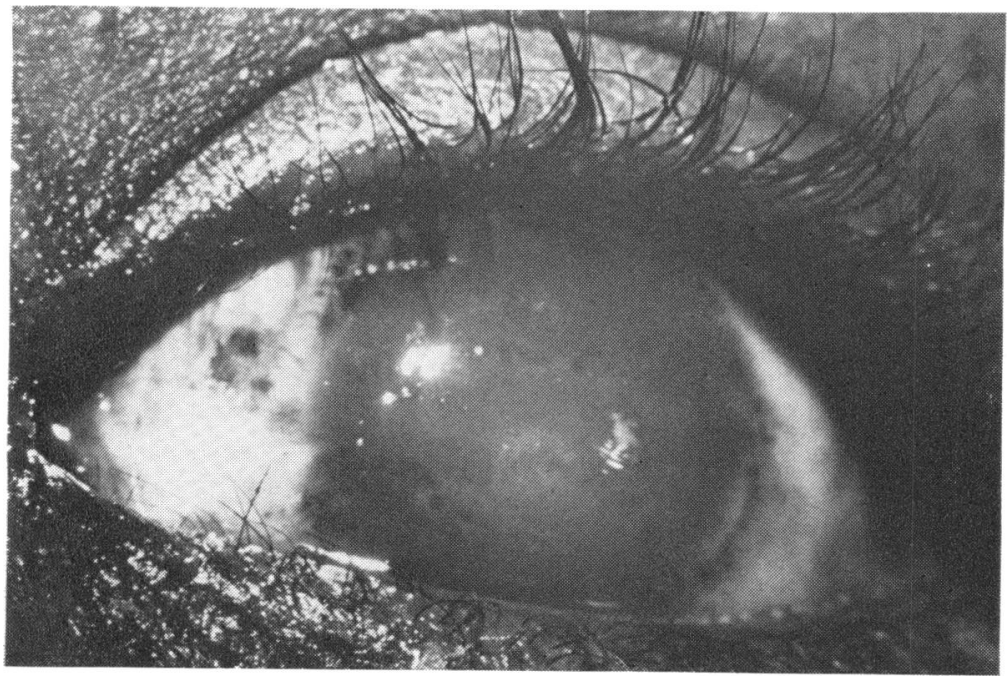

Fig. 3 Opaque cornea in left eye of youngest brother with xeroderma pigmentosum 


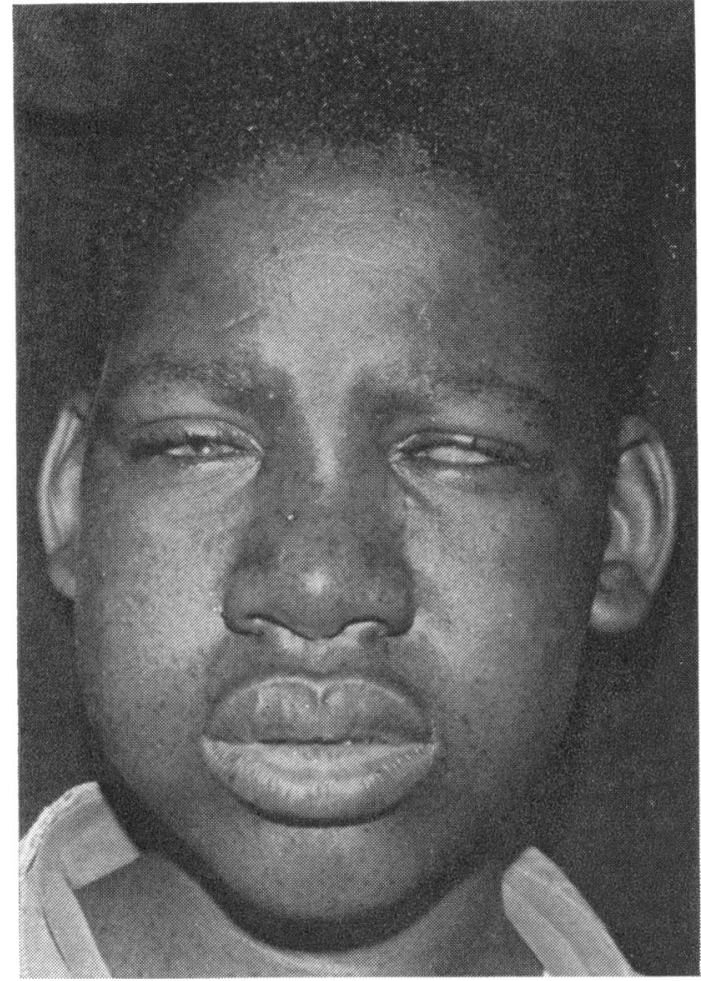

Fig. 4 Middle brother with xeroderma pigmentosum

mild skin manifestations of the disease and fairly marked ocular involvement resulting in blindness. The more commonly associated ocular findings of xeroderma characterised by erythema of lid skin, conjunctival erythema with associated purulent discharge, pinguecula, pterygia, and limbal masses were not seen in the case reported. Increased limbal pigmentation of the conjunctiva was noted in this case, as it has been in cases of band-shaped nodular dystrophy. The appearance of a diffuse pannus-like infiltrate of the cornea is a common finding in xeroderma pigmentosum and similar changes have been seen in 3 other Bantu patients with the disease. All 3 patients were related.

Band-shaped nodular dystrophy of the cornea occurring in Bantus was first described by Etzine and Kaufmann (1964). Subsequently a report appeared of the condition in 65 cases of bandshaped nodular dystrophy in the Bantu (Freedman, 1973). The youngest case in that series was 50 years old; thus the patient in this report would appear to be the youngest Bantu to be described with bandshaped nodular dystrophy. The cornea in this patient showed a fairly advanced degree of the condition, being stage 3 out of 5 stages as classified by Freedman (1973). The occurrence of bandshaped nodular dystrophy in conjunction with a disease entity characterised by known susceptibility to actinic rays may lend credence to the theory that band-shaped nodular dystrophy may be aetiologically related to degeneration by actinic rays, as has been suggested. Furthermore, the young age at which this occurred would substantiate the premise that the corneas were susceptible to degeneration by actinic rays. In this regard the youngest brother (Case 3) is of great interest. His right cornea which was clear, may well have been protected from the effect of actinic rays by the ptosed lid. His left cornea, unprotected by a ptosed lid, showed the typical opacification as seen in xeroderma pigmentosa.

It is now known that the skin of patients with xeroderma pigmentosum is most sensitive to light, having a wavelength of 280 to $310 \mathrm{~nm}$ (Lynch, 1934). The light of this wavelength has a damaging effect on the DNA molecule. Studies (Cleaver, 1968, 1970; Epstein et al., 1970) indicate that cells of xeroderma pigmentosum are unable to undergo normal repair synthesis of DNA after ultraviolet exposure. The defect may be due to the absence of any enzyme normally present which clears the damaged part of the DNA molecule and allows it to repair. This

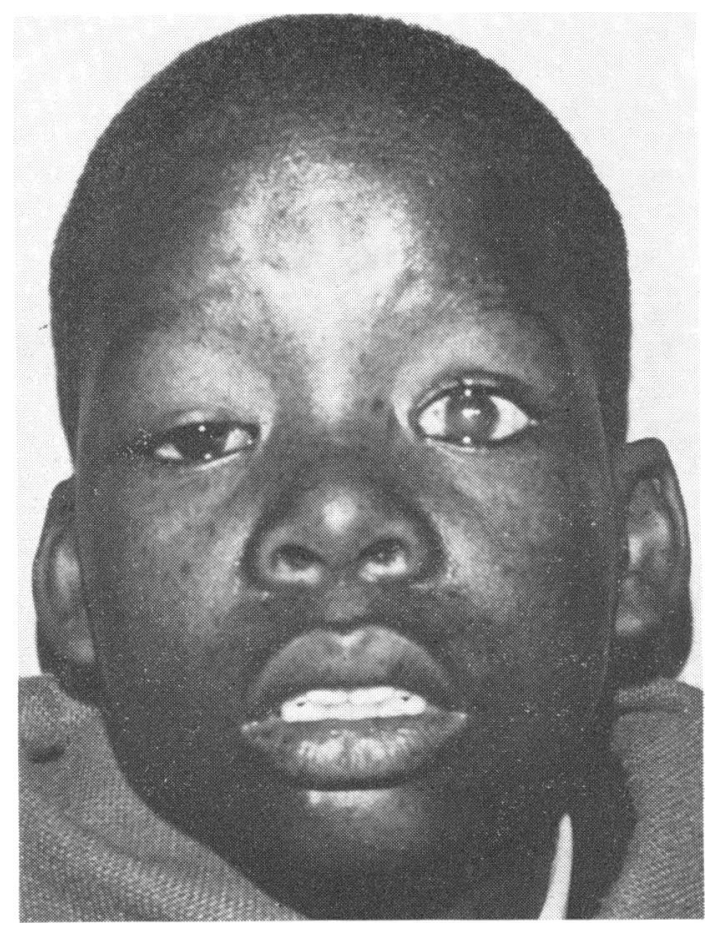

Fig. 5 Youngest brother with xeroderma pigmentosum 


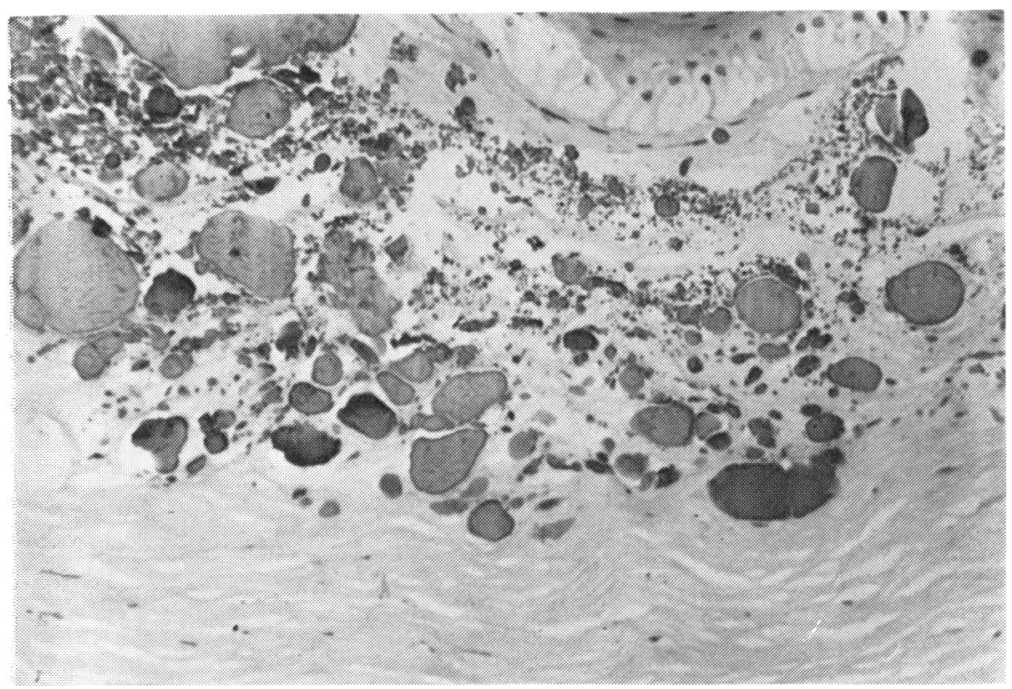

Fig. 6 Hyaline deposits in superficial stroma with irregularity of superficial stroma

enzyme defect may be responsible for the corneal damage seen in xeroderma pigmentosum and perhaps for the occurrence of band-shaped nodular dystrophy of the cornea in the case reported. The enzyme defect may be genetically determined in xeroderma pigmentosum and possibly occurs as an ageing process in cases of band-shaped nodular dystrophy not occurring in association with xeroderma pigmentosum, as most of the cases of nodular dystrophy have occurred in elderly patients. However, this is speculation, but the occurrence of
2 actinically determined corneal degenerations in the same patient may indicate a similarity in aetiology not previously suspected.

The treatment of both xeroderma pigmentosum and band-shaped nodular dystrophy is surgical, which is done for optical purposes in the late stages of both conditions.

I thank the Medical Superintendent of the Baragwanath Hospital for permission to publish this paper.

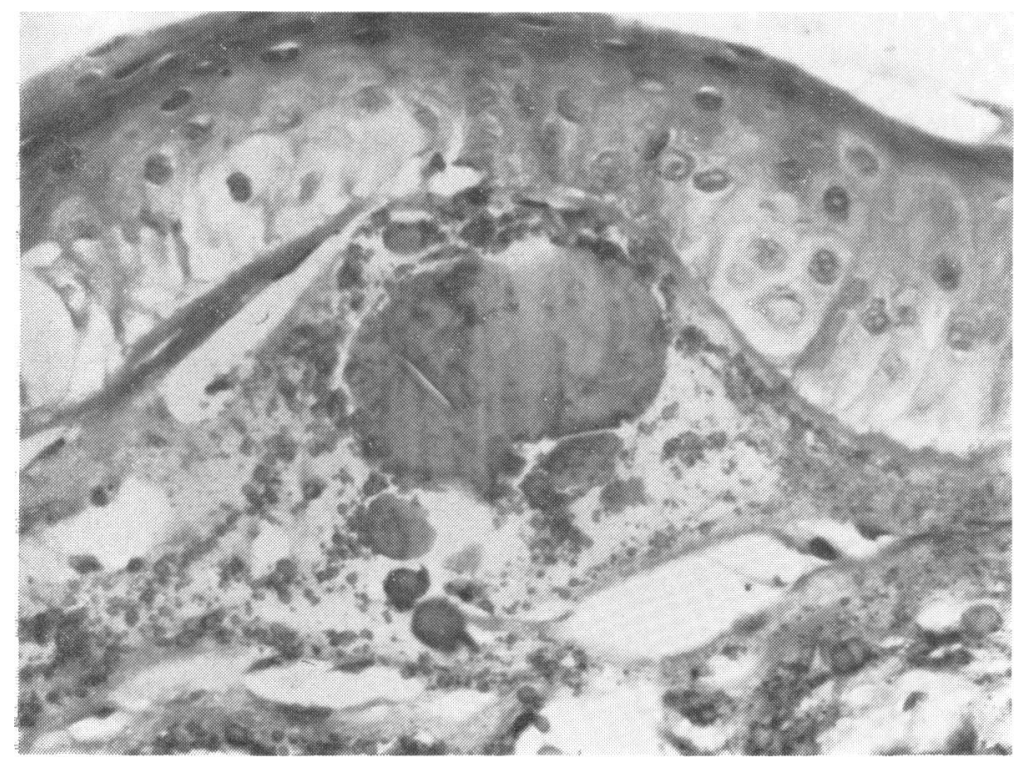

Fig. 7 Hyaline deposit in stroma eroding basement membrane 


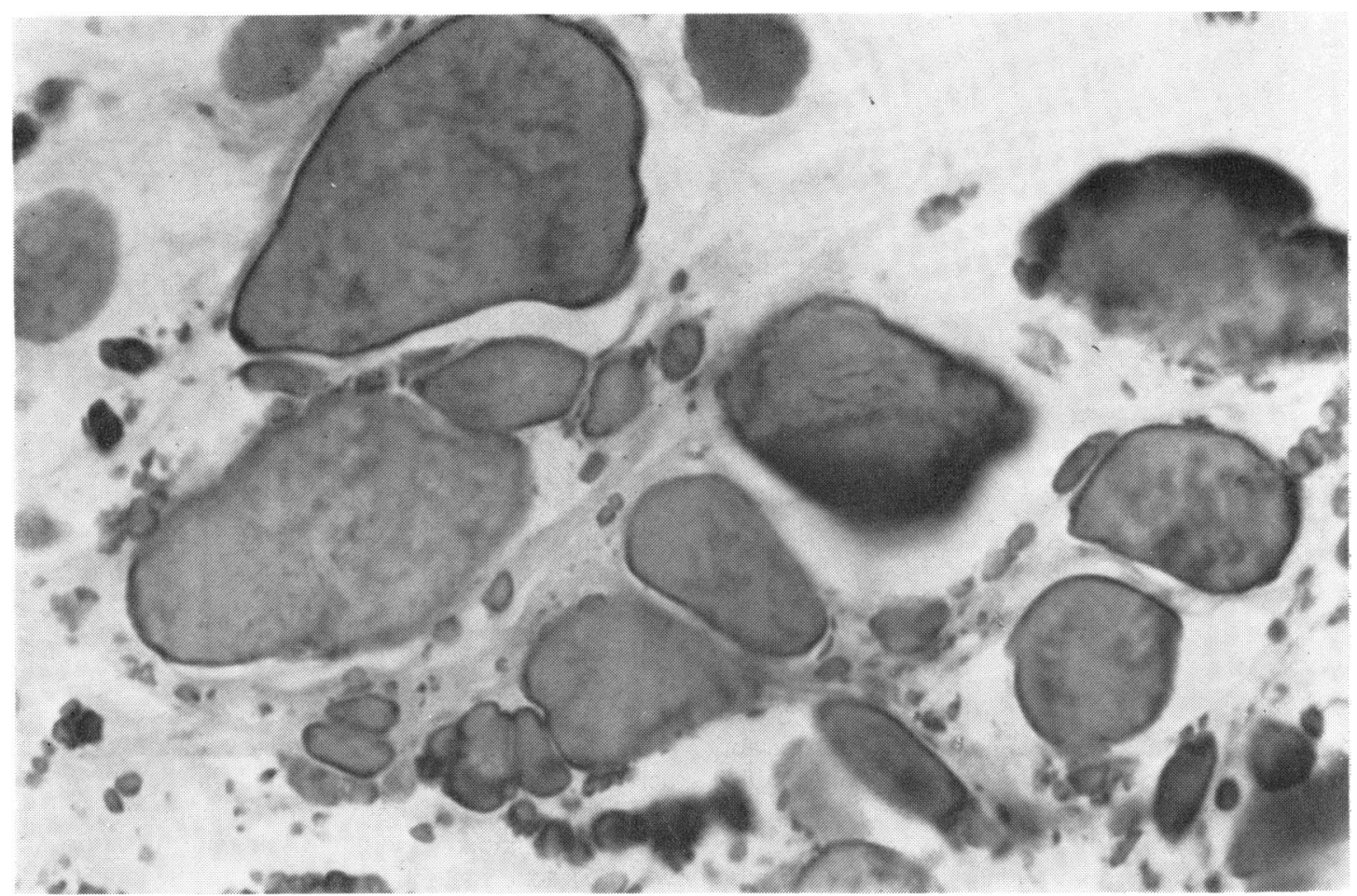

Fig. 8 High power of hyaline deposits in cornea

\section{References}

Cleaver, J. E. (1968). Defective repair replication of DNA in xeroderma pigmentosum. Nature (London), 28, 652-656.

Cleaver, J. E. (1970). DNA damage and repair in lightsensitive human skin disease. Journal of Investigative Dermatology, 54, 181-195.

Epstein, J. H., et al. (1970). Defect in DNA synthesis in skin in vivo. Science, 168, 1477-1478.

Etzine, S., and Kaufmann, J. C. E. (1964). Band-shaped nodular dystrophy of the cornea. American Journal of Ophthalmology, 57, 760-763.

Freedman, J. (1973). Band-shaped nodular dystrophy of the cornea. South African Archives of Ophthalmology, 1, $149-156$.

Giller, H., and Kaufmann, W. C. (1959). Ocular lesions in xeroderma pigmentosum. Archives of Ophthalmology, 62, $158-161$.

Harris, L. C., and Keet, M. P. (1960). Xeroderma pigmentosum: A report on six cases in South African Bantu children. Journal of Pediatrics, 57, 759-768.

Loewenthal, L. J. A., and Trowell, H. C. (1938). Xeroderma pigmentosum in African negroes. British Journal of Dermotology, 50, 661-671.

Lynch, F. W. (1934). Xeroderma pigmentosum. Archives of Dermatology and Syphilology, 29, 858-873.

Sevel, D. (1963). Xeroderma pigmentosum with ocular complications. British Journal of Ophthalmology, 47, 657689.

Targovsky, I., and Loewenthal, L. J. A. (1956). Xeroderma pigmentosum: Report of a case in a Bantu child. South African Medical Jourral, 30, 984-986. 